\title{
Is time for thinking to vaginal microbiome to prevent sexually transmitted diseases?
}

\begin{abstract}
Mini Review
Sexually Transmitted Diseases (STDs) represents a major concern for public health systems worldwide: its prevalence is higher all over the world. ${ }^{1}$ In US about 12 millions of new cases occur each year and, surprisingly, also in developing countries STDs are very frequents beeing the second cause of health loss in childbearing women. ${ }^{1}$ Among all age groups adolescents between 10 and 19 years are the higher risk category: multiple sexual partners and unprotected sexual encounters seem to be the reason why of this relationship. ${ }^{1}$ The role of vaginal microbiome in humans is peculiar and unique between all the mammalian: the humans species are the only one with a relative abundance of lactobacillus species in vagina (more than $70 \%$ ) if confronted with the other mammals that present not more than $1 \%$ of lactobacilli in vaginal microbiota (Figugr 1). ${ }^{1}$ During the past decade there has been an increasing interest in molecularbase, culture-independent techniques to study microbiome and the National Institute of Health has universally recognized the potential of molecular techniques to further understand human bacterial communities initiated the Human Microbiome Project (HMP) more than ten years ago (2007). ${ }^{2}$
\end{abstract}

The HMP targeted the genitourinary system because it has been well established for more than a century that a lot of bacteria are present within the human vagina and that the imbalance within the microbial environment could be associated with a lot of diseases. ${ }^{1}$ Many researches have demonstrated that modifications in the vaginal microbiome, such us in Bacterial Vaginosis, affect susceptibilty to gynecologic infections including cervicovaginitis, postoperative infections and HIV and HPV infections. ${ }^{3-7}$ Vaginal microbiome in healthy women is a lactobacilli-dominated environment that contribute to mantain $\mathrm{pH}$ under 4.5 and to produce lactic acid, hydrogen peroxyde, bacteriocins together with biosurfactants and coaggregant activities able to counteract the growth of gram negative anaerobes bacteria such as G. vaginalis, Bacteroides, Mobiluncus spp and E. Coli: when this microenvironment changed and this equilibrium was broken (decreased of lactobacilli spp and increased in gram negative bacteria) vaginal $\mathrm{pH}$ increases determining Bacterial Vaginosis (BV). ${ }^{8,9}$

Increased in vaginal bacterial diversity. such as in $\mathrm{BV}$, with the well-Known vaginal ecosystem modifications, seems to be associated with Sexually Transmitted gynecological infections: Chlamydia trachomatis, Neisseria Gonorrhea, Trichomonas vaginalis, Human Papilloma Virus (HPV) and Herpex Simplex Virus 2 (HSV-2) infections are substained and related to previous $\mathrm{BV} .{ }^{10-13}$ So that treat $\mathrm{BV}$, also in asymptomatic women, seems to be crucial for preventing STDs. Unfortunately the CDC (Center for Disease Control) recommended treatment regimen (metronidazole $500 \mathrm{mg}$ orally twice a day for 7 days or metronidazole/clindamycin vaginal gel/cream one full application intravaginally at bedtime for 7 days) seems to be uneffective to control BV recurrences and mostly of the women treated according to $\mathrm{CDC}$ requirements have high recurrence rates
Volume 2 Issue I - 2018

\author{
Marco Bertini \\ R\&D Department, Laboratori Baldacci SPA, Italy
}

Correspondence: Marco Bertini, R\&D Department, Laboratori Baldacci SPA, Italy, Tel +39050 31327I, Email bertini@baldaccilab.com

Received: January II, 2018 | Published: February 22, 2018

in 6-12 months. ${ }^{14}$ Metronidazole or Clindamycin treatment do not prevent recurrences of $\mathrm{BV}$ infections because the healthy lactobacilli vaginal population is rarely reconstituted. ${ }^{14}$

Thus, there could be clinical advantages for the use of biotherapeutic agents (prebiotics/probiotics/synbiotics) together with CDC standard regimen for $\mathrm{BV}$ eradication and healthy vaginal microenvironment restoration. ${ }^{15}$ McFarland and Elmer defined Biotherapetic agents in 1995 as "living microorganisms that are used to prevent or treat human diseases by interacting with natural microbial ecology of the host" ${ }^{15}$ Considering BV a predisponing factor for STDs acquisition and considering BV the worldwide prevalent vaginal infection in childbearing age women, it seems to be obvious the relationship between BV and Sexual Transmitted Diseases (STDs): controlling and normalizing vaginal microbiome in all childbearing age women could represent a relatively inexpensive and correct strategy to counteract STDs transmission and infections. Considering that $\mathrm{CDC}$ recommended therapies failed to control relapses of BV (almost $40 \%$ of relapses at 3 months and $50 \%$ of recurrences rate at 6 months $)^{16}$ during the last years the use of biotherapeutic agents has been proposed and suggested to restore vaginal microbiome in $\mathrm{BV}$ women. ${ }^{15}$ The results belonging to the long-term use of a symbiotic (probiotic + prebiotic) vaginal tablets containing a selected lactobacillus populations (Lactobacillus rhamnosus BMX 54) plus a selected prebiotic (lactose) vaginally applied following CDC recommended regimen seems to be intriguing and support the use of this sinergistic and alternative therapy ${ }^{16-25}$ for a definitive restoration of the healthy vaginal microbiome able to counteract STDs infections and trasmission.

Controlled clinical trials performed in more than 800 women affected by BV and treated with standard of care (metronidazole) followed by a long-term course of this vaginal symbiotic clearly demonstrated a significative reduction of the recurrence rates of BV. ${ }^{16-25}$ Recently this synergistic approach (standard of care followed by Lactobacillus rhamnosus BMX 54 plus lactose vaginal tablet application) has shown to be useful also in controlling HPV infections 
in 117 women affected by bacterial or yeast infections and PAP smear abnormalities. ${ }^{25}$ This symbiotic topical implementation for at least six months have demonstrated to be able to re-establishing normal vaginal microflora (eubiosis) after standard of care treatment and, surprising, PAP smear alterations (Figure 2) or HPV clearance (Figure 3) have shown to significant improve in the group of women treated for longterm with Lactobacillus rhamnosus BMX 54 plus Lactose. These data support the use of long-term probiotics vaginal implementation after CDC recommended therapy not only to restore vaginal eubiosis but also to control HPV transmission and infection confirming that "is time to thinking to vaginal microbiome" to control STDs infection and that this simple and unexpensive approach could become "a keystone" in the STDs prevention and treatment.

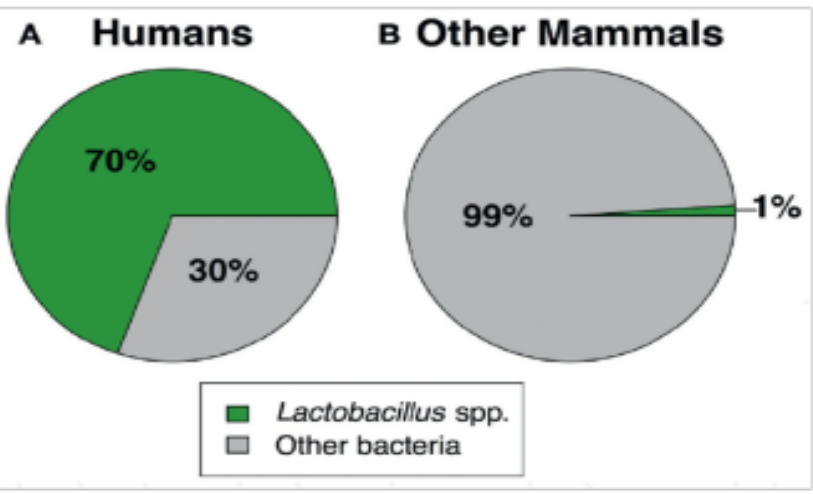

Figure I Mean vaginal relative abundance of Lactobacillus spp. vs other bacteria in humans $(A)$ and nonhumans $(B)$. I

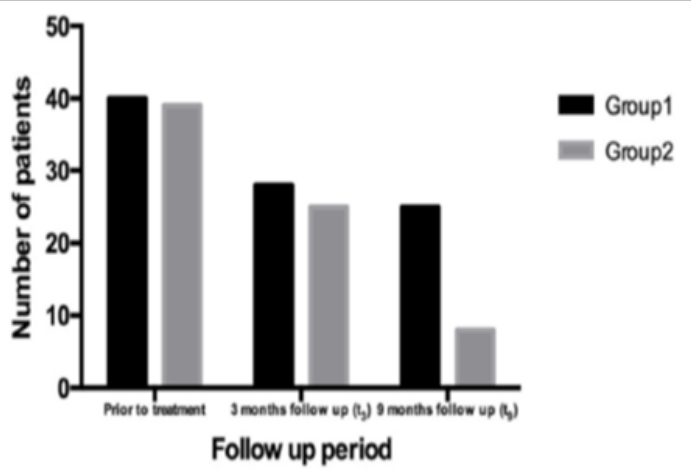

Figure 2 Trend of HPV abnormalities resolution in the two groups (group I- short probiotics implimention group, $n=60$; group 2- long probiotics implemetion group, $n=57 ; p=0.041$.

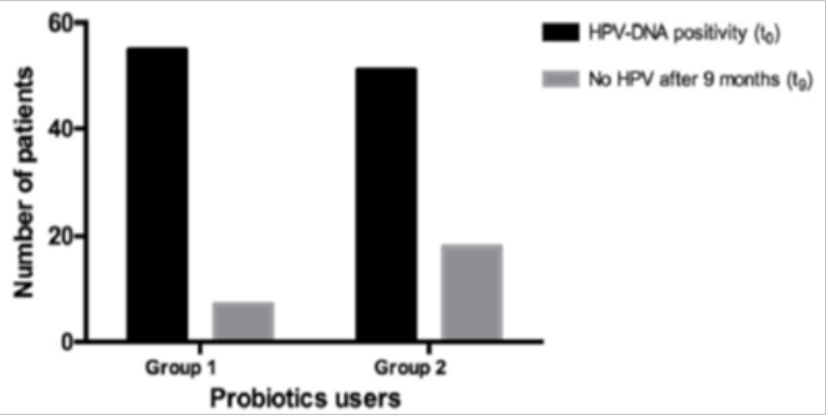

Figure $3 \mathrm{HPV}$ clearance at the end of follow up period ( $\mathrm{t} 9$ ) in the two groups (group I - short probiotics implemention group, $\mathrm{n}=60$, group 2 - long probitics implemention group, $n=57), \mathrm{HPV}$ clearence was significantly higher in the long term probiotics users than in the other groups $(\mathrm{p}=0.04 \mathrm{I})$, to before treatment; tq; after 9 months follow up.

\section{Acknowledgements}

None.

\section{Conflict of Interest}

The author declare there is no conflict of interest.

\section{References}

1. Bertini M. Bacterial Vaginosis and Sexually Transmitted Diseases: Relationship and Management. Fundamentals of Sexually Transmitted Infections-Intech; 2017.

2. Human Microbiome Project Consortium. Structure, function and diversity of the healthy human microbiome. Nature. 2012;486:207-214.

3. Schwebke JR. Gynecologic consequences of bacterial vaginosis. Obstetrics and Gynecology Clinics of North America. 2003;30(4):685694.

4. Cherpes TL, Meyn LA, Krohn MA, et al. Association between acquisition of herpes simplex virus type 2 in women and bacterial vaginosis. Clinical Infectious Diseases. 2003;37(3):319-325.

5. Martin HL, Richardson BA, Nyange PM, et al. Vaginal lactobacilli microbial flora and risk of human immunodeficiency virus type 1 and sexually transmitted disease acquisition. J Infect Dis. 1999;180(6):18631868

6. Cu Uvin S, Hogan JW, Caliendo AM, et al. Association between bacterial vaginosis and expression of human immunodeficiency virus type 1 RNA in the female genital tract. Clinical Infectious Diseases. 2001;33:894-896.

7. Cohen CR, Lingappa JR, Baeten JM, et al. Bacterial vaginosis associated with increased risk of female to male HIV-1 transmission: A prospective cohort analysis among African couples. PLOS Med. 2012;9(6):e1001251.

8. Doderlein A. Das scheidensekret und seine bedeutung fur puerperalfieber. Bakteriology. 1892;11:699.

9. Thomas S. Doderlein's bacillus: Lactobacillus acidophilus. Journal of Infectious Diseases. 1928;43(3):218-227.

10. Cherpes TL, Meyn LA, Krohn MA, et al. Association between acquisition of herpes simplex virus type 2 in women and bacterial vaginosis. Clinical Infectious Diseases. 2003;37(3):319-325.

11. Wiesenfeld HC, Hiller SL, Krohn MA, et al. Bacterial vaginosis is a strong predictor of Neisseria gonorrhea and Chlamydia trachomatis infection. Clinical Infectious Diseases. 2003;36(5):663-668.

12. Dareng EO, Ma B, Famooto AO, et al. Prevalent high risk HPV infection and vaginal microbiota in Nigerian women. Epidemiol Infect. 2015;144(1):1-15.

13. Brotman RM, Klebanoff MA, Nansel TR, et al. Bacterial vaginosis assessed by gram stain and diminished colonization resistance to incidentgonococcal, chlamydial and trichomonal genital infection. Journal J Infect Dis. 2010;202(12):1907-1915.

14. Koumans EH, Kendrick JS. For the CDC Bacterial Vaginosis Working Group. A public health program and research agenda. $C D C$. 2001;28(5):292-297.

15. Al Ghazzewi FH, Teser RF. Biotherapeuticc agents and vaginal health Journal of Applied Microbiology. 2016;121(1):18-27.

16. Bertini M. Is Lactobacillus rhamnosus BMX 54 vaginal application a strategy to counteract bacterial vaginosis recurrences? In: Ben-Rafael Z, editor. Proceedings of $18^{\text {th }}$ World Congress on Controversies in Obstetrics, Gynecology \& Infertility; USA; 2013: p. 24-27.

17. Parma M, Stella Vanni V, et al. Probiotics in the prevention of recurrences 
of bacterial vaginosis. Alternative Therapies in Health and Medicine. 2014;20(Supple 1):52-57.

18. Recine N, Musciola A, Moreira E. The benefits of topical vaginal therapy with Lactobacillus case sub-rhamnosus in preventing bacterial vaginosis relapses. In: Communication and Posters for the $\mathrm{X}$ National iBAT Conference Naples. 2018;1(Suppl 1):26-28.

19. Recine N, Palma E, Domenici L, et al. Longterm probiotic implementation to re-create a balanced vaginal ecosystem: A promising boost against HPV. In: Infection Communication and Poster of International Scientific Conference probiotics and prebiotics, Hungary; 2016.

20. Recine N, Palma E, Domenici L, et al. Restoring vaginal microbiota: Biological control of bacterial vaginosis. A prospective case-control study using Lactobacillus rhamnosus BMX 54 as adjuvant treatment against vacterial vaginosis. Arch Gynecol Obstet. 2016;23(1):101-107.

21. Marcone V, Calzolari E, Bertini M. Effectiveness of vaginal administration of Lactobacillus rhamnosus following conventional metronidazole therapy: How to lower the rate of recurrences. New Microbiol. 2008;31(3):429-433.
22. Marcone V, Rocca B, Lichtner M, et al. Long-term vaginal administration of Lactobacillus rhamnosus as a complementary approach to management of bacterial vaginosis. International Journal of Gynecology \& Obstetrics. 2010;110:223-226.

23. Stojanovic N, Plecas D, Plesinac S. Normal vaginal flora, disorders and application of probiotics in pregnancy. Archives of Gynecology and Obstetrics. 2012;286(2):325-332.

24. Rossi A, Rossi T, Bertini M. The use of Lactobacillus rhamnosus in the therapy of bacterial vaginosis. Evaluation of clinical efficacy in a population of 40 women treated for 24 months. Arch Gynecol Obstet. 2010;281(6):1065-1069.

25. Palma E, Recine N, Domenici L, et al. Long-term Lactobacillus rhamnosus BMX 54 application to restore a balanced vaginal ecosystem: a promising solution against HPV-infection. BMC Infectious Diseases. 2018;18(13):2-7. 